\title{
Coronavirus Pandemic in Morocco: Measuring the Impact of Containment and Improving the Learning Process in Higher Education
}

\author{
Fatima-Zohra Hibbi, Otman Abdoun, and Haimoudi El Khatir
}

\begin{abstract}
The higher education in Morocco knows a real challenge due to the consequences of covid19. This challenge was effect by the transformation of the teaching mode from face to face (learning at school) into a distance learning (home based learning).

This paper reports comparative studies of technologies that used in Moroccan Higher education and the constraints encountered the E-learning mode. The objective of this article is to describe how to success the higher education in this period of confinement via a case study and recommend a proposed solution. The experiments and results that presented in this article are based on data which collected from a private professional training institution and the collaboration of the learners in the field of study.
\end{abstract}

Index Terms-Covid19, e-learning, higher education, learning process.

\section{INTRODUCTION}

When we think of "face-to-face education" we associate it into the following elements: teacher, learner and the classroom. However, in this type of education, the learners often work in team, manipulate, produce, create a small workshops group in which learners take responsibility and present their work. The teacher provides more creative and productive activities, and trying to make the learners at the center of their interest.

On the other hand, other type of education that used recently called "E-Learning". The learners have the ability to track a course anywhere and anytime. This kind of education lacks support and assistance of the trainer when the learner is faced with a problem situation or the learning process is inadequate for each learner style. Some researchers proposed an Intelligent Tutoring system to support learners and give them a feedback [1]. Others suggest a smart detector of learning style to adapt the learning process in E-learning mode [2].

On March 17th, 2020, the Moroccan government

Manuscript received June 14, 2020; revised October 28, 2020.

Fatima-Zohra Hibbi is with Abdelmalek Essaadi University, Larache, Morocco (e-mail: Fatima.zohra.official@gmail.com).

Otman Abdoun is with the Department of Computer Science at Pluridiscipli-nary Faculty Larache in Abdelmalek Essaadi University, Morocco (e-mail: abdoun.otman@gmail.com).

El Khatir Haimoudi is with the Department of Computer Science in Ab-delmalek Essaadi University, Larache, Morocco (e-mail: elkhatir@gmail.com). announced the closure of all universities, schools and private establishment due to the global effect of "corona virus". Due these circumstances, the minister of education declared to use E-learning as an alternative. Nevertheless, the Ministry of National Education, Vocational Training, Higher Education and Scientific Research in Morocco have categorically denied having announced "a blank year" for all school levels except for some. However, several neighboring and Arab countries have announced the end of the 2019-2020 school years; taking the case of Tunisia as an example of a Maghreb country that reveals the end of the school year for all levels of education with the exception of baccalaureate candidates due to the pandemic of Coronavirus. According to a press conference, the ministry highlighted that the rest of the program for the other levels will be completed during the next school year, the gaps of 4 to 5 weeks to be completed [3]. On the other hand, the current state of higher education in European countries such as France, Belgium, Italy, etc. has announced the reopening of schools, colleges and universities. The return to school will be done in a progressive way according to calendars with the respecting of the sanitary protocol.

Over the last few months, the majority of learners have successfully adapted; however, the community of professionals and the experts in the E-learning filed offered a typology of different types of courses. The result of their research shows that the type named "flexible" or "HyFlex": (courses in which students can choose between online tracking mode (synchronous or asynchronous) or face-to-face. This choice can be made during the course) is more applicable and suitable [4]. Nevertheless, this epidemic obliges them to use just E-learning. In this paper, we will present how we can successes the learning process using technology.

The aim of this paper is to analyze the effectiveness of the list of tools used in Moroccan higher education, and to investigate the student's problems during the confinement period. To confirm this, a study was set up to understand the students' challenges and their needs. The study was made successfully with the collaboration of professional training institution "CIEL Group" students.

The article is organized as follow: the second section will describe the major problems encountered during the confinement period to use the E-learning solution; after that, the authors will compare the educational tools used in Moroccan higher education; the section four will present the case study of a professional training institution; the last section will illustrate the results of the study. Finally, this 
article will be ended with a conclusion.

\section{THE INVOLVED CONSTRAINTS IN E-LEARNING}

The interruption of the current year (depending on the considered hemisphere) greatly disrupts the situation of a large number of students and teachers. E-learning strategies can reduce the impact of such interruption. Richer countries are better armed to switch to these online alternatives, which certainly require a great deal of effort. In Countries under development, the situation is highly contrasted and, without appropriate measures, the inequality of opportunity, which is already reaching extreme and intolerable levels, will widen further. Many students (trainees) do not have desks, books, Internet access and laptops at home. What we need to avoid or minimize as far as possible is to increase these inequalities and exacerbate the impact of this crisis on the learning of disadvantaged students. Professor Mohammed Guedira noted that teachers have never worked under pressure in confinement, and many of them have no basic notions of new technologies [5]. All the more, so the learners were not prepared for this kind of exercise and they had not knowledge about this pedagogical device.

However, those were involved in the decision-making process are all called to take this indisputable state of affairs into consideration before moving on to the digitization of examinations and assessments, in order to avoid any injustice to these victims of the early digitization of educational content. It is also obligatory to look at some general remarks which can be summarised as follow:

1) The issues are certainly big and important but the obstacles seems huge [6];

2) As a result of geographical disparities, students from poor families or simply living in cantons not covered by Internet networks have been deprived of their right to learn [6];

3) The content of some courses were built gradually and according to the affective complicity that animates the exchanges and fuels the debate between the teacher and the learner [6].

On April 4th, 2020, The Ministry of National Education has announced the resumption of the distance education process. While students were preparing for their exams, Mr. Amzazi has noted that the scheduling of exams depends on the "epidemiological situation" and the "conditions for lifting the confinement" [7].

Based on a survey conducted by the National Higher School of Arts and Crafts of Casablanca (ENSAM Casa), the Economist pointed out that students do not understand the online course. Indeed, in terms of understanding the courses, $48 \%$ of the 741 students surveyed are confused, a quarter said they fully understand their courses, while a second quarter confessed not to have a clear understanding of their lessons. In fact, $79 \%$ of the students declared that they have never used E-learning platforms. They add that "even the best platforms and internet connections and the best IT tools do not necessarily guarantee good teaching" [8].

For all these reasons, and many others, we made a study on the major problems encountered by students of the "CIEL" institute, specializing in computer development. It was found that the issues encountered are related to problems of Internet access $(55.56 \%)$, interaction between teachers and students $(22.22 \%)$ and the uses of technological tool $(11,11 \%)$. The Fig. 1 describes the main obstacles to keep up the students with e-learning process:

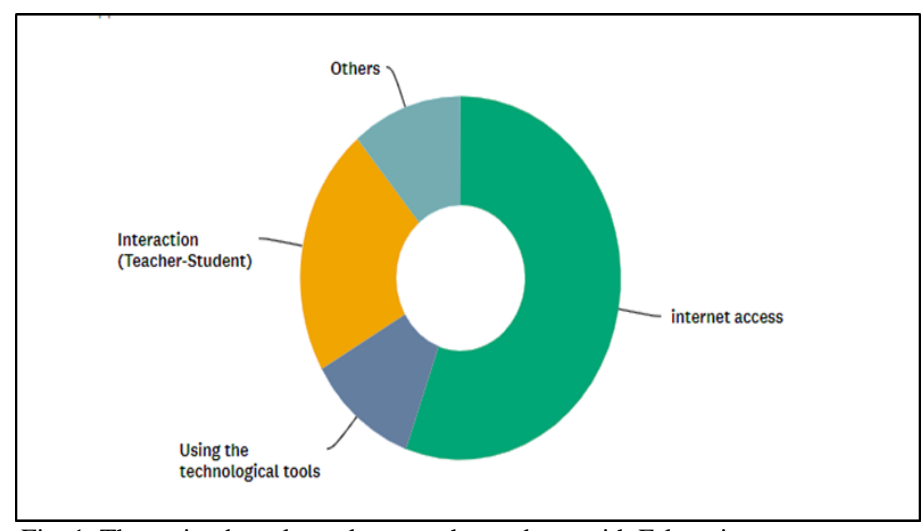

Fig. 1. The main obstacles to keep up the students with E-learning process.

\section{COMPARISON OF THE ONLINE EDUCATION TOOLS}

The high education in Morocco recommends using an online environment instead of the classical form of education due to the epidemic of covid-19. Abdelmalek Essaadi university and like other Moroccan universities, has put the disposal of their teachers and students a platform to follow their courses via explanatory videos and course materials as described in Fig. 2.

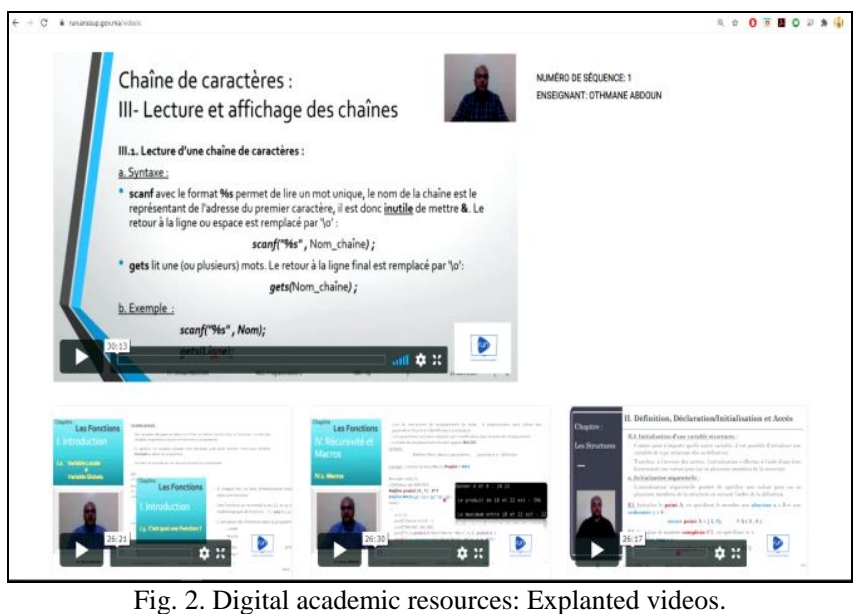

The Moroccan Ministry of Education has proposed other tools such as the Diffusion of university courses on TV channels (ARRYADIA TV) and radios (SNRT Radio) to facilitate access to courses. To improve the interaction between teachers and students; some teachers decided to create videos and upload them in their YouTube channel or planning a live on Facebook to explain their courses.

According to the University Center of Computer Resources (CURI) which is a part of the university and to address this critical situation in order to find out urgent solutions, several virtual classrooms have been created via Google Classroom platform. The statistics until the first week of April 2020 are summarized in the Fig. 3.

These statistics do not include the other courses deposited in the university's Moodle platform [9]: 


\begin{tabular}{|l|l|}
\hline Etablissements & $\begin{array}{l}\text { Classes } \\
\text { virtuelles }\end{array}$ \\
\hline Ecole de Chimie & 2 \\
\hline Ecole Supérieure de l'Education et de la Formation & 69 \\
\hline Ecole Nationale de Commerce et de Gestion & 39 \\
\hline Ecole Nationale des Sciences Appliquées & 65 \\
\hline Ecole Supérieure de Technologie & 35 \\
\hline Faculté des Lettres et des Sciences Humaines & 94 \\
\hline $\begin{array}{l}\text { Faculté des Sciences } \\
\text { Faculté des Sciences Juridiques, Economiques }\end{array}$ & 296 \\
\hline Sociales & et \\
\hline TOTAL & 222 \\
\hline \multicolumn{1}{|l|}{ Fig. 3. The number of virtual classes for each establishment [10]. }
\end{tabular}

Concerning the professional training institution that has about 20 to 90 students in a class. The teaching processes are based on real time mode using different tools like Hangout Meets, zoom application, etc. To succeed the online education process, we need to pick a tool that contains the following criteria's:

1) Connecting on real-time mode to have more interaction with the learners;

2) The students and the teachers should have the possibility to share their screens in case to show their application and their course;

3) In case on unestablished of internet, recording and uploading options are required;

4) A discussion room is needed to facilitate the communication;

5) The teachers need to send the course and the practice exercise file;

6) Sometimes the teacher needs a board to explain some concepts and to make a summary of the course;

The Table I presents a comparison of an online education tools according to the following criteria:

TABLE I: COMPARISON OF AN ONLINE EDUCATION TOOLS

\begin{tabular}{|c|c|c|c|c|c|}
\hline Criteria & $\begin{array}{ll}\frac{0}{00} & \Xi \\
0 & \vdots \\
0 & 0 \\
0 & \frac{\pi}{0}\end{array}$ & 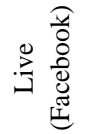 & 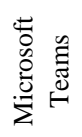 & 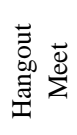 & 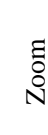 \\
\hline Real-time mode & & & $\mathrm{X}$ & $\mathrm{X}$ & $\mathrm{X}$ \\
\hline Communication (Chat) & $\mathrm{X}$ & $\mathrm{X}$ & $\mathrm{X}$ & $X$ & $X$ \\
\hline Attached File & $\mathrm{X}$ & $\mathrm{X}$ & $\mathrm{X}$ & $X$ & \\
\hline Share screen & & & $\mathrm{X}$ & $X$ & $X$ \\
\hline Board for explanation & & & & & $X$ \\
\hline Remote control & & & & & $\mathrm{X}$ \\
\hline Record the session & & & & $\mathrm{X}$ & $\mathrm{X}$ \\
\hline
\end{tabular}

We analyzed these tools and we found that Microsoft teams, Hangout Meet and Zoom application offer a suitable options according to the criteria presented above. However, to use the Microsoft and google tools a membership on a university is required; also you should to have an academic Email that has the following format: Me@MyUniversity.com The objective of the article is to propose a solution for the major situation to succeed the higher education in the period of confinement using an online platform.

\section{Case Study of a Private Professional Training INSTITUTION}

"CIEL" Group in Tangier (Moroccan city) is the first vocational training school to start using the specialized Digital Workspace as GEFPro developed by Mr. Amine BAHHAR in 2016. Indeed, GEFPro can be defined as a numerical extension of the school. It is a multi-user and multi-functional platform.

GEFPro is now available in version 2.1, which is characterized by simplicity, flexibility, speed and security. This space, which has been specially developed to bring the administration closer to the student, and to facilitate access to information in a personalized way, it will allow each student to access many features.

On March, 14th, 2020, following the instructions from the Ministry of Education; the institute decided to use "Zoom" Application as a best solution to apply it in this confinement period. To access to the online course, the institution updates their system and creates a new action called "online course (Real-Time mode)" in order to help students to continue their studies. The Fig. 4 illustrate the "Online course" space:

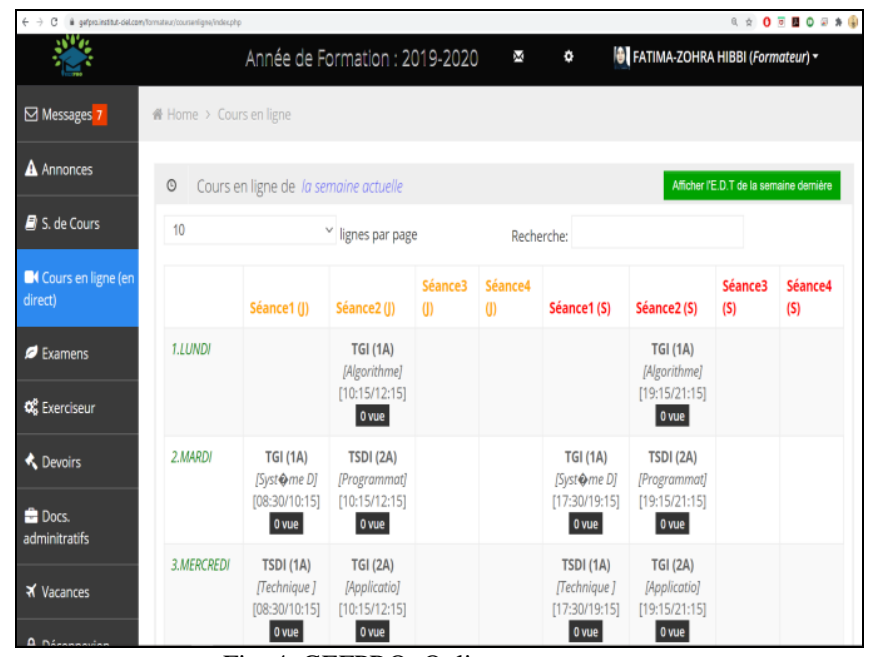

Fig. 4. GEFPRO: Online course space.

\section{RESUlTS AND DISCUSSION}

To analyze the effectiveness of this tool and the impression of students toward the online course, a study was set up by a structured questionnaire filled by 24 students of "CIEL group", specialized in computer development (1st year and 2nd year). The questionnaire contains close-ended items for the students to respond to. These types of questions are quick to analyze it [11].

The questionnaire was constructed using survey monkey solution and the link was shared via Gmail platforms to get the responses from the selected group. The survey monkey tool was used for the data collection and it's a great tool for analyzing the results. The choice of this specialization is not arbitrary; this field requires a lot of practice and demonstration.

The study makes us to know the constraints and obstacles encountered during the learning process. The Fig. 5 illustrate that the most of students in the 1st year found that the online courses are enjoyable in contrast the second year students found it so boring (100\%). According to their answers of the reason (why they feel bored?). They affirmed that the problem was the animation of the session.

The Table II describes the student's missing in online 
course; the responses are divided according to their level. Concerning the students of the 1 st year, declared that there is a lack of course organization, enthusiasm and communication. For the students of the 2nd year, they announced that they are missing the entertainment space, communication and others enthusiasm. The diversification of these results obtained refers to various factors: the age, the strategy of teaching in online course, the structure of pedagogical course, etc.

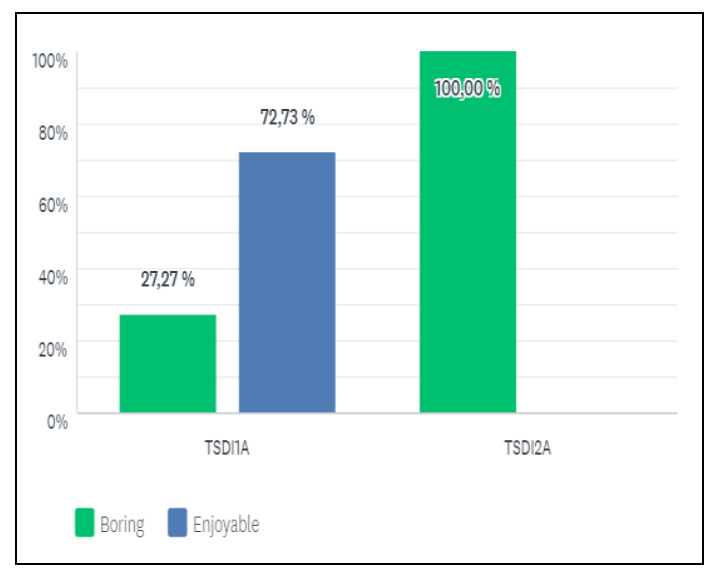

Fig. 5. The impression of the student according to their level.

TABLE II: THE STUDENT’s Missing IN ONLINE COURSE

\begin{tabular}{lcc} 
Ranking & - & - \\
& $\mathrm{X}$ & $\mathrm{X}$ \\
\hline Competition & $\mathrm{X}$ & - \\
Communication & $\mathrm{X}$ & $\mathrm{X}$ \\
The entertainment aspect & - & $\mathrm{X}$ \\
Enthusiasm & - \\
The organization of the courses
\end{tabular}

The attendance rate implies the success or failure of online course. The figure below shows the attendance rate of students by gender. After the analysis of the collected data, we notice that the majority of the students who don't manage to follow the course and sometimes check the recording course are female with a rate of $18,18 \%$, in the other side the male attend with a rate of $81,82 \%$. We can analyze this separation with the Moroccan culture that oblige women to do the Home Works and neglects her attendance to online course.

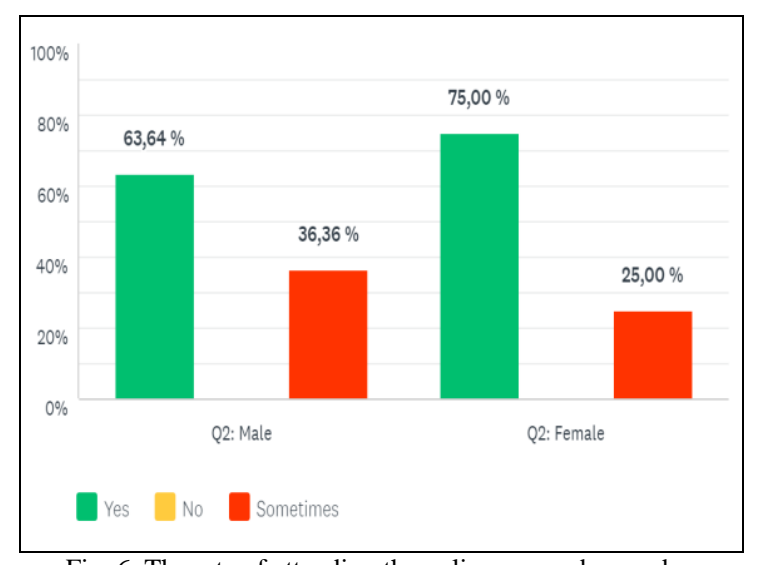

Fig. 6. The rate of attending the online course by gender.
The study presents the causes that explain the setback encountered in online course during this month, particularly among second-year students. The study reveals two main reasons, namely material reasons presented in the problem of internet access and sometimes computer breakdowns. And pedagogical reasons presented in the teaching methods, as well as the tools used to animate the session, and the comings and goings of the learners that disrupt the course of the session. This article analyzes the major problems and proposed a solution in pedagogical terms which is a platform that contains collaboration spaces, course recording and real-time mode. We asked the students of their satisfaction with this proposition and we obtained the results illustrated in Fig. 7. The figure bellow present that $81 \%$ of the respondents satisfied with the proposed solution.

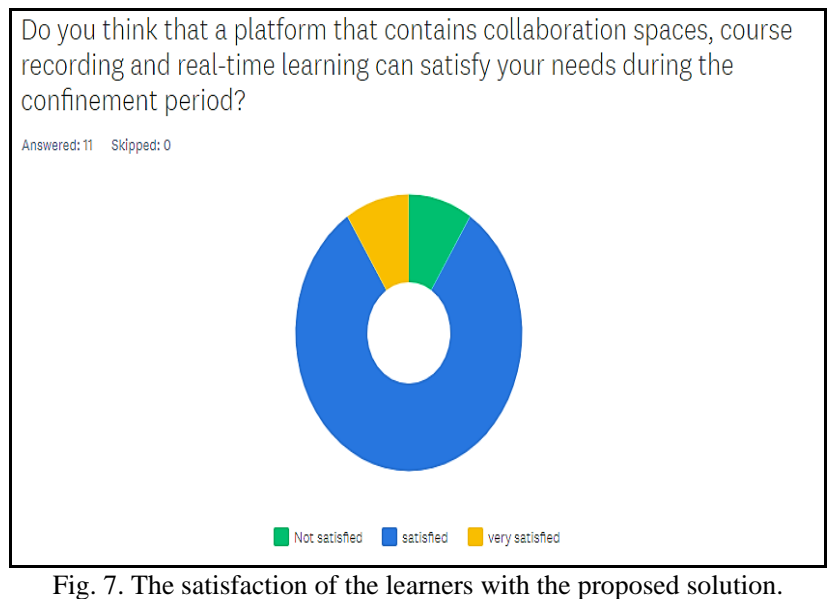

\section{CONCLUSION}

All education systems have the same mission: to overcome the crisis of learning and find a response to the pandemic. Today, the challenge is to limit as much as possible the repercussions on learning, but also to build on this experience in order to progress more rapidly in the future. The aim is dual: to manage the current crisis and to reflect on how education systems can recover more vigorously, both led by actors with a renewed sense of responsibility and better equipped to understand the urgency and the need to address the inequality of opportunity and to ensure quality education for every student.

However, Morocco switched from country 1.0 (using paperwork and web 1.0) to country 4.0 (using technology and web 4.0) with the coronavirus crisis, thus gaining several years of ground. According to speech of the president of the University Moulay Ismail (UMI) of Meknes, he valued a considerable achievement, and recommends promoting E-learning, based on the gains made during the health crisis of Covid-19 [12]. According to him, nobody can deny the effect of this crisis on the immediate and spontaneous adoption of information and communication technologies by the various actors in primary, secondary and university education to ensure pedagogical continuity for children and students [12]. The responsible parties have shown a great deal of courage and boldness, it must be acknowledged. I believe that the pandemic has been despised. In terms of management, our approach is based on making do with what 
we have and what we know how to do.

In this article, we analyze the major challenges encounter Moroccan students in a professional training institution using online courses. This study allows us to have the main causes that prevent the success of online training. To solve these problems and to succeed the higher education system, we propose a platform that contains collaboration spaces, course recording and real-time mode. The students react positively and satisfied with the proposed solution. The results of this contribution will help the education system to develop a sustainable strategy to meet the challenges faced by students during a pandemic of this nature.

\section{CONFLICT OF INTEREST}

The authors declare no conflict of interest.

\section{AUTHOR CONTRIBUTIONS}

All authors have contributed equally to this manuscript and agreed to the final version.

\section{REFERENCES}

[1] F. Z. Hibbi, O. Abdoun, and H. E. Khatir, "Integrating an intelligent tutoring system into an adaptive e-learning process," Recent Advances in Mathematics and Technology. Applied and Numerical Harmonic Analysis, 2020.

[2] F. Z. Hibbi, O. Abdoun, and H. E. Khatir, "Smart detector of learner style," presented at 2019 International Conference on Optimization and Applications, 2019.

[3] L. Loucham, Tunisie Covid-19: Fin De L'année Scolaire Sauf Pour Le Baccalauréat, May 2020.

[4] B. Beatty, "Hybrid courses with flexible participation: The hyflex course design," doi: 10.4018/978-1-4666-4912-5.ch011, 2013.

[5] Y. E. Khamlichi, "Enseignement à distance au Maroc : quels sont les principaux obstacles?" April 2020.

[6] J. Boumaajoune. (2020). Enjeux et défis d'une numérisation précoce. [Online]. Available: http://albayane.press.ma/\%EF\%BB\%BFenjeux-et-defis-dune-numeris ation-precoce.html

[7] FNANCES News. (2020). Coronavirus : Amzazi annonce la reprise des cours à distance dès demain 4 mai. [Online]. Available: https://fnh.ma/article/alaune/coronavirus-amzazi-annonce-la-reprise-d es-cours-a-distance-des-demain-4-mai

[8] B. Khansaa. (2020). Enseignement et confinement: le passage à l'E-learning est difficile. [Online]. Available : https://www.lebrief.ma/5816-enseignement-et-confinement-le-passage -le-learning-est-difficile

[9] D. Louiz. (2020). L'enseignement à distance au Maroc à l'heure du Covid-19. [Online]. Available: https://www.libe.ma/L-enseignement-a-distance-au-Maroc-a-1-heure-d u-Covid-19_a117908.html

[10] D. Louiz (2020). L'enseignement à distance au Maroc à l'heure du Covid-19. [Online]. Available: https://www.libe.ma/L-enseignement-a-distance-au-Maroc-a-l-heure-d u-Covid-19_a117908.html

[11] L. Cohen, L. Manion, and K. Morrison, The Methodology of Educational Research, 2008.

[12] K. H. Mbaye. (2020). enseignement: quel modèle après le covid19. [Online]. Available: https://leseco.ma/enseignement-quel-modele-apres-le-covid-19/

Copyright (C) 2021 by the authors. This is an open access article distributed under the Creative Commons Attribution License which permits unrestricted use, distribution, and reproduction in any medium, provided the original work is properly cited (CC BY 4.0).

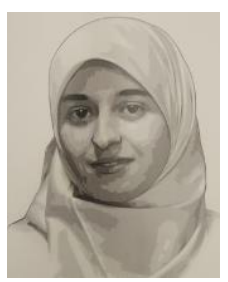

Fatima-Zohra Hibbi is a Ph.D. candidate at the Department of Computer Science at Abdelmalek Essadi University. She had her engineering in pedagogy and multimedia. Her research interest includes learning analytics, e-learning and $\mathrm{AI}$ in learning.

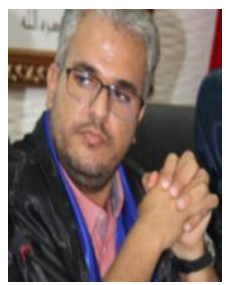

Otman Abdoun is a professor of computer science at Abdelmalek Essaadi University. His current research includes the optimization, problem solving and learning technology.

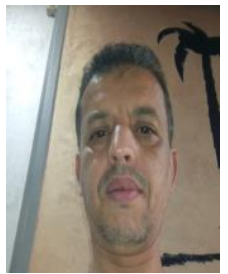

Haimoudi Elkhatir is a professor of computer science at Abdelmalek Essaadi University. His current research includes the optimization and neural network. 